\title{
Optimal Site Selection for Temporary Accommodation of People Who Have Been Injured by Natural Disasters in Kamyaran, Iran
}

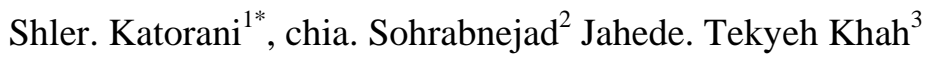 \\ ${ }^{1}$ Academic Center for Education, Culture and research (ACECR),kurdestan,iran. \\ ${ }^{2}$ Academic Center for Education, Culture and research (ACECR),kurdestan,iran. \\ ${ }^{3}$ Academic Center for Education, Culture and research (ACECR),kurdestan,iran. \\ sh.katorani@yahoo.com
}

\begin{abstract}
The present study intends to predict the optimal places for temporary accommodation of people who have been injured by natural disasters in Kamyaran, Iran, where there is a potential and the capability to rapidly settle people affected by the crisis, and to help manage the natural disaster crisis by creating the necessary facilities to identify suitable places for temporary accommodation using proper and scientific planning. Based on the purpose, this is an applied research, and the research study method based on the nature and subject of the research is descriptive and analytical.

Based on the descriptive-analytic research methodology, after determining the effective criteria for temporary accommodation site selection, that was selected from the literature review and according to the study area and available information and data, weighing the criteria and the indicators were performed according to the professional experts in crisis management using the Pairwise Comparison Technique and Expert Choice software. Then using the AHP model and Arc GIS software, the layers of each criterion were integrated according to each determined weight, and finally the optimal locations for temporary accommodation in Kamyaran was determined according to the criteria for the management of urban crisis. According to the results, land use indices with a weight of 0.38 and distance from hazardous facilities with a weight of 0.3 and their criteria are more important in locating the optimal area for temporary residence of the injured people.
\end{abstract}

Keywords: Temporary Settlement, Geographic Information System, Hierarchical Analysis, Kamyaran

\section{Introduction}

\section{1-1. Statement of the Problem}

In spite of the remarkable advances in technology and the unthinkable achievements of the past century, man is still incapacitated by natural disasters such as earthquakes, floods and droughts, and occasional exposure to many financial losses. In this regard, unprincipled construction and neglecting the risks in a region, disregard to the distance of sensitive uses and residential areas from faults and rivers, exacerbates the catastrophe. Meanwhile, the earthquake is inevitable, and has always led to great human tragedies, and numerous financial and human losses and other negative impacts, so that it has presented itself as one of the most serious humanitarian threats. Confronting this natural disaster and reducing its negative impacts is one of the issues that has been highly regarded by governments in the last century. So far that the 1990s was called the decade of reducing the effects of natural disasters. Therefore, the management of the earthquake crisis is specifically important and valuable and is evaluated and analyzed for specific use. In this regard, the success rate and functional efficiency of the urban elements are closely related to the establishment and organization of the element in the spatial-geographic position, which is subject to certain principles, rules and mechanisms. Failure to observe the necessary principles and rules not only reduces the functional efficiency of urban elements, but also causes physical and environmental damage to the urban environment such as irregularities, turbulence, early environmental erosion, inappropriate access and, in general, distance from the characteristics of a desirable urban environment. One of the issues raised in crisis management, especially in the field of unexpected events, is the optimal site selection in order to accommodate citizens during or after the incident. One of the most important issues considered by the responsible organizations in the field of crisis management after the occurrence of unexpected events is the selection of proper and safe area for temporary accommodation of the injured population according to the unique features in site selection which can be used as a tool in logical site selection for those who were injured by the disaster. 
Due to the concentration of population and economic capital and the importance of this province in various aspects on the one hand, and due to the high seismicity of the province on the other hand, the necessity and importance of studying and planning precisely to reduce human and social damage caused by earthquake is essential. One of the issues that has always been the focus of the responsible organizations in crisis management is the selection of a place for the emergency or temporary accommodation of the population affected by accidents. In Iran, site selection emergency accommodation is usually provided experimentally by relief agencies in the aftermath of an incident, regardless of the standards required.

On the other hand, from an environmental point of view, the best place to deploy for a type of user is the place where the lowest load and pressure is imposed on the environment and the user suffers the least damage or pressure from the environmental changes caused by accommodation in the place (Sadeghi, 2007). Therefore, the necessity of planning, management and providing appropriate solutions in the temporary accommodation of the affected population before the earthquake seems essential.

Experience suggests that, if the criteria are not already set, at the time the program for the creation of a temporary accommodation is initiated, unpredictable factors interfere with the program and affect the quality of the decision by various means. The most important factor for advanced preparation is the recognition of the degree of vulnerability in a crisis as well as prioritizing and identifying solutions to prevent and control the risks that can occur (Ahari, 1990).

Selection of the criteria, determining the relative and general weight, production of information layers for spatial modelling and combining the information form the basis of the present study, GIS environment provides the proper tools to access the above process for analytical and spatial modelling.

Preparing suitable places for deployment of relief agency centers after natural disasters and accommodation of the affected people is one of the important issues in programming and managing the crisis. For this purpose, the present study aims to predict optimal temporary accommodation after the natural disasters in Kamyaran, in order to be able to manage more efficiently under crisis conditions and to minimize the disadvantages of the natural disaster crisis by creating the necessary facilities in the appropriate places for temporary accommodation.

Doing this research is essential due to the following reasons:

- Lack of an efficient and standard model for temporary accommodation site selection after the incidents

- Unidentified temporary accommodation sites after the accident in Kamyaran

The most important objective of this research was to provide a pattern for planning and site selection in order to provide temporary accommodation for victims of natural disasters to obviate their primary requirements after the event that shall begin immediately after the emergency accommodation phase starts. Of the other targets of this research, the following could be mentioned:

- Developing the criteria for selecting these places

- Identifying suitable sites for temporary accommodation

Samad-zadegan (2006) in an article deals with the use of GIS in optimal site selection for accommodation of victims of natural disasters by taking advantage of fuzzy theory. In the above article, he studies the appropriate and optimal site selection for deployment of citizens after the disaster using the unique features of GIS through fuzzy logic.

Varnoosfaderani et al (2011), in their article entitled application of GIS in site selection for urban temporary accommodation (Isfahan case study) studied the case. In this article, they considered the subject of GIS application in temporary accommodation site selection in urban centers (Isfahan case study) during and after the crisis in the region six, Isfahan. Research method was descriptive-analytical and using ARC/GIS software the site selection map for temporary urban accommodation centers with a crisis management approach was provided. The results show that according to several indicators, installations and equipment in the area, suitable temporary accommodation areas were identified and action has been taken to prioritize them, which resulted in identifying three partially and approximately suitable regions for this purpose.

Shojaian and Alizadeh (2014) in an article investigated site selection for multifunctional spaces with the aim of post-earthquake crisis management (case study of Shoshtar's old texture). The research was multi-purpose including identifying and locating with the aim of managing the post-earthquake crisis in the old texture of Shushtar. According to the results of the research, the best places were in the South and South West of Shushtar.

Giweh-chi et al. (2015), investigated site selection for temporary post-earthquake accommodation using GIS and AHP technique in Shiraz. The results showed that accessibility criteria and spatial characteristics among other standards and selection of suitable site for temporary accommodation of injured people are of higher importance. 
Tudes (2011), in a research first using GIS and AHP technique and different criteria such as type of use, slope and quality of land, heights, etc., for the city of Adana, one of the most dangerous earthquake regions in Turkey, provided a map of zoning the relative hazard of earthquake and then used it for site selection in some urban utilities.

Katrina et al. (2011) focused on site selection in low-risk areas in Macedonia. They used the GIS software and AHP model and socioeconomic and environmental criteria to locate low-risk areas.

\section{3- Materials and Methods}

Multi Criteria Decision Making (MCDM) is a decision-making tool, which is used for complex multi-criteria issues and evaluates issues quantitatively and qualitatively. Given that proper decision making about complex processes in the world is difficult, MCDM models were created to make things easy (Malchfsky, 2006). One of the most convenient ways for environmental projects, land use and management of agricultural sector, natural resources and water resources is MCDM (Chen et al., 2009).

In decision-making based on multi-criteria analysis, several criteria are simultaneously examined on a limited number of options. In the present study, to select the evaluation criteria for locating the appropriate sites for temporary accommodation in the area, features such as ease of standard measurement and being associated with temporary accommodation were considered.

In general, this study consisted of two phases, the first phase was to zone prone temporary accommodation sites and the second phase was the identification of camps in separated areas.

To determine the proper areas for temporary accommodation, MCDM method was used. The following steps were taken in this regard:

\section{3 -1- Identifying the Evaluation Criteria}

Identification and selection of impact factors in site selection was among important steps in this study. The more the identified factors are consistent with ground facts, the more the site selection results would be satisfying (Farajzada-Asl, 2005).

\section{3-2 - Prioritizing the Selected Criteria}

\section{3- 2-1- Designing the Questionnaire for Weighting the Criteria}

For weighting the group criteria, main criteria, sub-criteria and indicators in the study, questionnaires were designed. The questionnaire used were composed of two parts: one part was related to weighting the group criteria using the pairwise comparison due to the strong theory, high precision and ease of use. The next part of the questionnaire was related to weighting the main criteria, sub-criteria and the related indices. This part of the questionnaire was weighted using the Delphi method. The aforementioned questionnaire were provided to the relevant experts. Each of the group criteria, main criteria, sub-criteria and each index were weighted by the experts. In this way, the priority and importance of each group criteria was determined according to experts' opinion.

\section{3-2 -2- Calculating the Weight of Group Criteria}

In this study for final weighing of the group criteria, AHP method was used (Ghodsi-pour, 2006). The questionnaire results were entered the Expert Choice software and the desired group criteria were weighted and prioritized. After entering the opinion of each expert, the amount of incompatibility determined by the software was controlled and in cases where the inconsistency rate was greater than 0.1 , they were returned to eventually reach an incompatibility rate of about 0.1 or less. Then, for each of the factors, the experts' opinions were taken in the geometric mean software and the final weight of the group criteria was determined.

\section{3-3- Zoning the Prone Ranges for Temporary Accommodation}

For all information layers based on their degree of importance derived from the analysis of the questionnaire, linear model was prepared. The factors with existing layers were included in the linear model and the rest of the factors which did not have the information layer were eliminated. Finally, the linear model with the weight of the existing layers were prepared and after overlaying in the GIS environment, the ultimate map of the zones of the areas prone to temporary accommodation were prepared. The final map indicates areas of high utility.

\section{4- Results}

\section{4-1- Analysis of the Criteria}

After compilation of the criteria identified in this study using multi-criteria evaluation method using AHP and Delphi, the group criteria, the main criteria and sub-criteria were weighted. First, using the Analytic Hierarchy Process (AHP), the weight of the group criteria was determined by pairwise comparison and the weight of each group criteria that shows their impact was calculated. For the main criteria and sub-criteria, the Delphi method and the questionnaire supplemented by experts, the weight of the main criteria and sub-criteria were obtained. 
Table 1: Weighting results of the criteria group, the main criteria for compatible use

\begin{tabular}{|l|l|l|l|}
\hline Criteria group & Final weight & Main Criteria & Final weight \\
\hline \multirow{4}{*}{$\begin{array}{l}\text { Proximity to } \\
\text { compatible use }\end{array}$} & \multirow{4}{*}{0.2} & Proximity to the green spaces and the park & 0.05 \\
\cline { 3 - 4 } & & Accessibility & 0.06 \\
\cline { 3 - 4 } & & Distance from military centers & 0.04 \\
\cline { 3 - 4 } & & Distance from health and medical centers & 0.03 \\
\cline { 3 - 4 } & & Distance from primary schools & 0.02 \\
\hline
\end{tabular}

Table 2: Weighting results of the criteria group, main criteria of incompatible use

\begin{tabular}{|l|l|l|l|}
\hline Criteria group & Final weight & Main Criteria & Final weight \\
\hline \multirow{4}{*}{$\begin{array}{l}\text { Proximity to to } \\
\text { incompatible use }\end{array}$} & \multirow{4}{*}{0.3} & Distance from high voltage power lines & 0.085 \\
\cline { 3 - 4 } & & Distance from high buildings and structures & 0.065 \\
\cline { 3 - 4 } & & population density & 0.080 \\
\cline { 2 - 4 } & Distance from the river & 0.070 \\
\hline
\end{tabular}

Table 3: Weighting results of the criteria group, the main environmental criteria

\begin{tabular}{|l|l|l|l|}
\hline Criteria group & Final weight & Main Criteria & Final weight \\
\hline Environmental & 0.12 & Slope & 0.12 \\
\hline
\end{tabular}

Table 4: Weighting results of the criteria group for land use

\begin{tabular}{|l|l|}
\hline Criteria group & Final weight \\
\hline Land use & 0.38 \\
\hline
\end{tabular}

\section{4-2- Mathematical model for assessing areas for the construction of a temporary camp}

After weighting the main criteria and sub-criteria, a mathematical model for evaluating the sub-criteria with the final weight higher than 0.14 was obtained. By multiplying the final weight in the corresponding sub-criteria, a mathematical model for evaluating the construction of camp was obtained. The sub-criteria used in the preparation of the mathematical model were divided into indices and in the last stage, by weighing these indices and overlaying the layers with maps, the zoning map was prepared.

$\mathrm{WLC}=0.05 \mathrm{~A}+0.06 \mathrm{~B}+0.04 \mathrm{C}+0.03 \mathrm{D}+0.02 \mathrm{E}+0.085 \mathrm{~F}+0.065 \mathrm{G}+0.080 \mathrm{H}+0.070 \mathrm{I}+0.12 \mathrm{~J}+0.38 \mathrm{~K}$

A: Proximity to the green space and the park

B: Accessibility

C: Distance from military centers

D: Distance from health and medical centers

E: Distance from primary schools

F: The distance from high voltage power lines

G: Distance from high buildings and structures

I: Distance from the river

$\mathrm{H}$ : Population density

$\mathrm{J}$ : Slope

$\mathrm{K}$ : Land use

\subsection{The Results of the Identification of Resources and the Criteria}

The results of identifying resources and criteria are presented as follows:

\section{4-3-1- Proximity to Compatible Uses}

The activities shall be coordinate with each other to be compatible and not to prevent each other's activity. To assess compatibility, four subscales (1- proximity to green spaces and parks, 2- proximity to cultural use, 3proximity to sports use and 4- proximity to religious use) were studied for each educational environment that will be reviewed and analyzed. 


\section{4-3-1-1- Proximity to the Green Space and the Park}

One of the most important issues in site selection is the identification of prone and suitable lands, in line with the purpose of locating. To this end, due to the conditions of the unplanned and unused lands and urban parks, they were identified as appropriate locations for temporary accommodation after the earthquake. In this stage, the methodology included proportional fitting of all green spaces. All the green spaces were assigned coefficients in proportion to the distance from the camps, so that, to a minimum distance that these uses should have from temporary accommodation sites, the highest coefficient, and to the rest of the distances lower coefficients were assigned in proportion to their distance from temporary accommodation sites. In addition, the distance from the green space was classified into five classes, which can be seen in the following map (figure 1).

\section{4-3-1-2- Distance from Military Centers}

Because of the need for public order and security of the residents in the temporary accommodation camps, access to military and police centers is one of the most important standards. In case of police stations, the best distance in terms of pedestrian access in times of crisis is about 400 meters and in case of garrisons in terms of their distribution in the city a distance of $2 \mathrm{~km}$ is considered (Figure 2).

\section{4-3-1-3- Distance from Health and Medical Centers}

Distance from health and medical centers must be such that in the event of natural disasters, access to these centers is not troubled (Figure 3).

\section{4-3-1-4- Distance from Primary Schools}

For ease of traffic, and to continue the motivation of education in children and adolescents, site selection for temporary accommodation of the injured people shall have the least distance from primary schools. According to the standard of the urban centers that consider basic education radius as far as $500-700 \mathrm{~km}$, due to the importance of children and adolescents' access to these centers in the event of crisis, the distance seems logical (Shi'a, 2006) (Fig. 4).

\section{4-3-2- Distance from Adversity and Incompatible uses}

\section{4-3-2- 1- Distance from High Voltage Power Lines}

Studying the vulnerability of a city against earthquake is an essential issue in order to recognize and consequently plan for decreasing the effects of a disaster. Therefore, one of the cases to study in order to identify proper temporary camp site is distance from high-voltage electricity lines (Figure 5).

\section{4-3-2- 2 - Population Density}

The population density and its role in planning is among the most important subjects of study in the field of urban planning. Given that with low population density in the city and balanced distribution, the city's vulnerability to earthquakes and natural disasters will be less, and conversely, high population density in the city means more casualties and damage in an earthquake (Abdollahi, 2004), the high-density areas, in site selection for temporary camp enjoy planning priority (Figure 6).

\section{4-3-2-4- Distance from the River}

Route of the river and its border when the rivers flood, is among the cases to consider at the time of site selection for schools. This is because non-compliance with this issue will create many risks and problems for the camps. There is a river in Kamyaran that crosses the city center and on the basis of site selection criteria, a border of $100 \mathrm{~m}$ width shall be considered for it (Figure 7).

\section{4-3-3- Natural Criteria}

In determining site selection measures for lands proposed for temporary accommodation in Kamyaran, natural factors include land slope that will be investigated in the following.

\section{4-3-3-1- Land Slope}

Factors and conditions that make and area favorable for establishing a camp and to provide the possibility of subsequent development are numerous. Land slope is one of the factors that can be used to locate these uses. In temporary camps after earthquakes, the general slope of the earth should be mild and between 2 and 6 percent. This degree of slope facilitates the drainage. A steep slope (higher than 10\%) is problematic and costly and should be avoided. In addition, smooth fields are likely to be flooded in the rainy season (Fallahi, 2007). Due to the fact that Kamyaran is a mountainous city and its topographic conditions are different than other cities of the province, in studying its slope for the construction of a camp, it should be noted that the places to be selected are in the best conditions to provide the comfort for the injured people. By studying the topography of the area in this study, the slope of this range was divided into four categories, and in this division, the lower the slope of the land, the more privilege is given to camp site selection (Figure 8). 


\section{4-3-3- Land Use}

Urban land use, are rated varying degrees of importance according to the social, economic, environmental factors, etc., so that some are quite interventable, others are relatively interventable and still others are noninterventable. In this study, barren lands, agricultural lands, private lands, green space and gardens are quite interventable; residential, and cultural facilities and equipment in the categories are relatively interventable and other land uses such as education, business, sports, etc., are in the non- interventable category (Figure 9).

\section{4-4- Results of Planning for Temporary Accommodation Camp}

At this stage with overlaying and integrating the map obtained in the GIS environment, the zoning map was obtained (Figure 10).

The map for planning the temporary accommodation camps in Kamyaran was prepared based on the AHP model. In this map, planning was carried out in areas where there was a good and very good desirability for the purpose of creating camps and considering land ownership, the susceptible areas for the camps were identified (Figure 11).

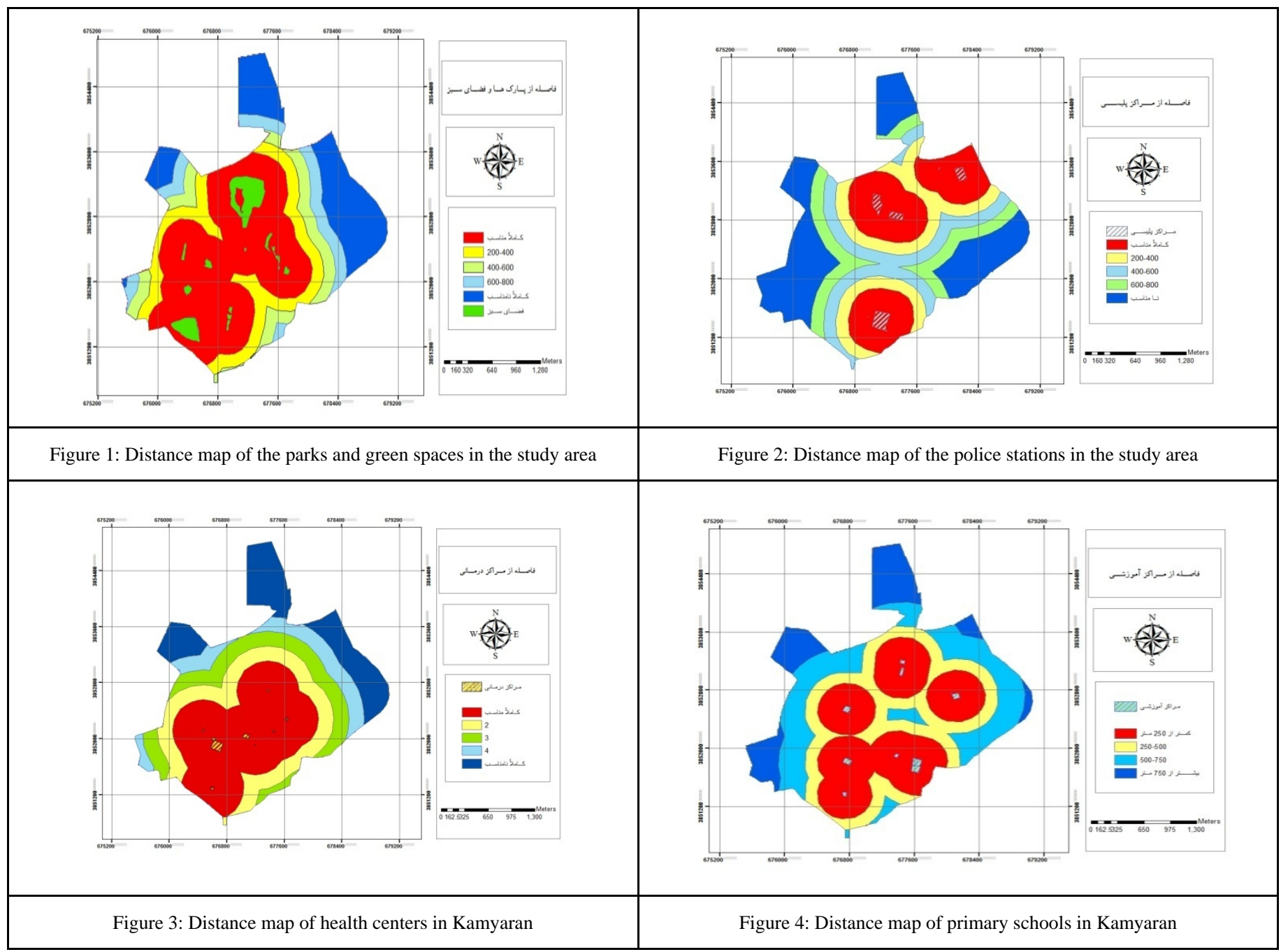




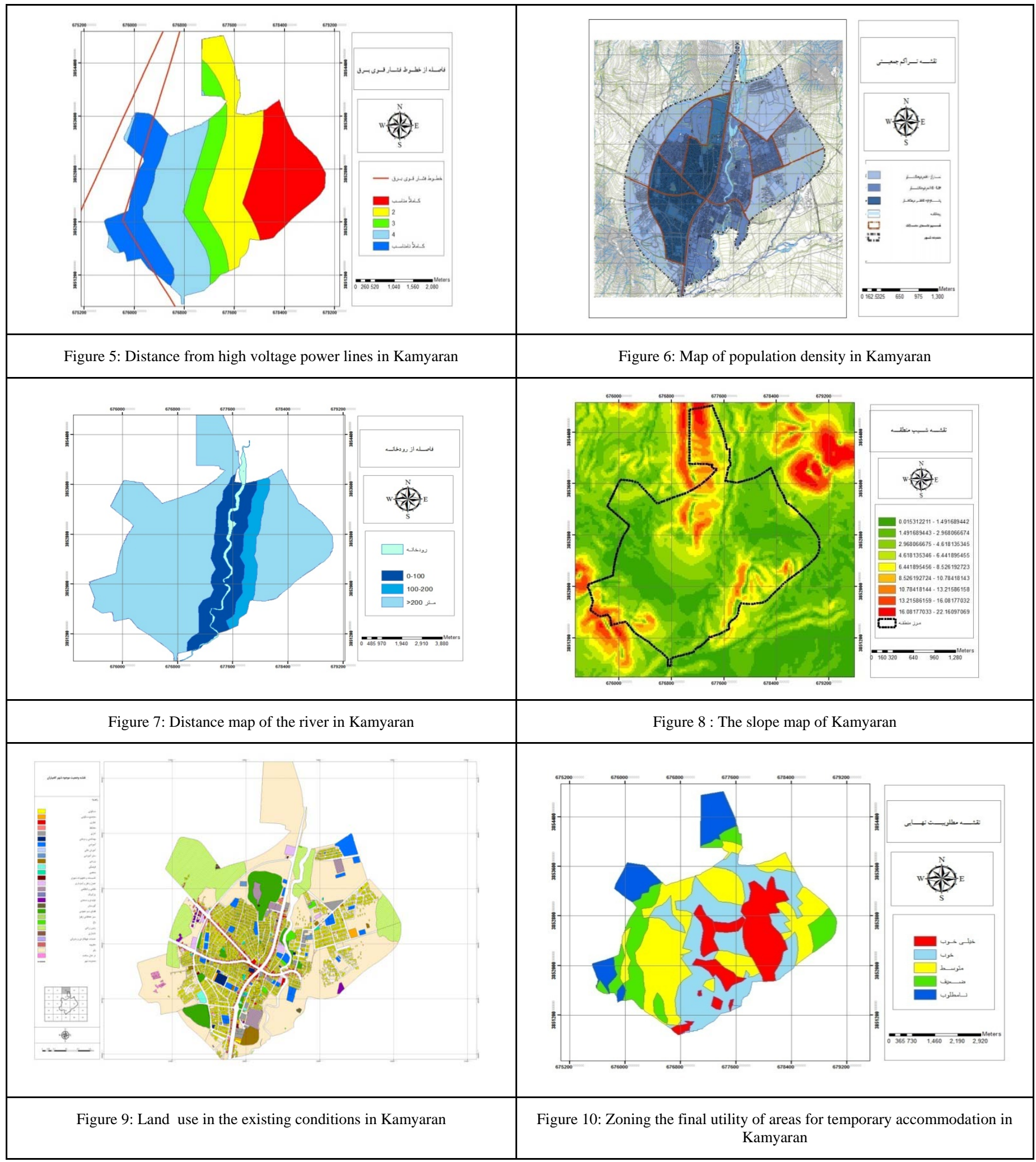




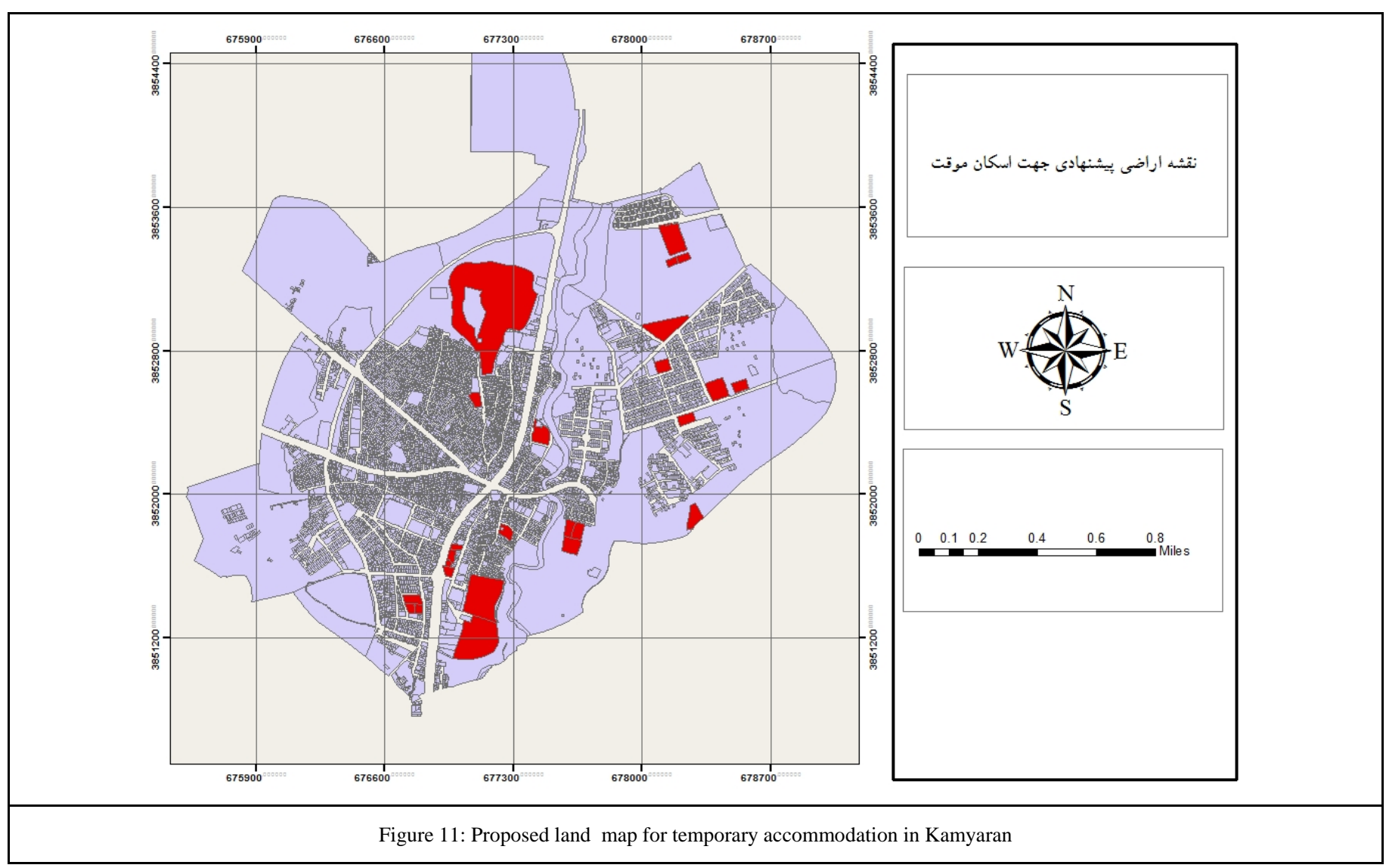

\section{Conclusion}

One of the issues in crisis management is the optimal selection for temporary accommodation during natural disasters or after the incidents. In this research, the authors achieved the goal of this study, which was to find places for temporary accommodation centers in Sanandaj, through the planning process and with the help of the principles and criteria developed by the GIS. It was attempted to determine the camp locations based on adjacency to a safe residential environment, proximity to arterial access, in the green space or in the open air, in the vicinity of the major access, covered by emergency centers, hospitals and treatment centers, distance from hazardous areas caused by an explosion of gas stations, high voltage towers, chemicals and inflammable materials with proportional and balanced distribution throughout the city. Moreover, by reviewing and analyzing accessibility, installations and other maps, some places are suggested as suitable locations for the establishment of accommodation centers.

Providing suitable locations for relief centers after disasters and settlement of the affected people is one of the important issues in planning and crisis management. For this purpose, in this article, the optimal places for temporary accommodation of the people injured by natural disasters in Kamyaran has been predicted and the researchers tried to help manage the crisis by identifying suitable temporary accommodation locations by integrating proper and scientific planning. The results and comparison of the results with other similar studies are sited in the following:

The most important results of this research are:

One of the issues raised in crisis management, especially in the field of natural disasters, is optimal site selection for accommodating citizens during the exposure or after the incident. Due to the interference of several factors and parameters in this problem, site selection for these areas has a lot of complexity. Considering the multiple factors involved in the optimal locating, use of GIS is necessary. By applying GIS and information such as maps and topography, road networks, users, petrol stations and health centers, etc., the capabilities of the systems could be used to identify low-risk areas with appropriate access. 
For this purpose, by defining situational, dimension and distance variables and by creating and setting up the above system by applying the proposed location profile in the database of urban information systems, the compliance of the characteristics of each of them with the criteria was determined. It was tried to determine the best accommodation location on the basis of the criteria provided in the proposed location in order to accommodate citizens after the occurrence of unexpected incidents. The results of the implementation and application of these concepts in the form of GIS, indicated the high ability of the idea presented compared to usual traditional methods.

The purpose of this article was to provide and formulate a scientific and precise framework in the system for planning and camp site selection for the homeless people, which in addition to the theoretical and experimental temporary accommodation bases, the best indicators in this field were dealt with. Finally, using an appropriate method in the multi-criteria decision-making area site selection for temporary accommodation in Kamyaran was determined. To achieve this goal, initially considering the capabilities of Boolean model in the attention to relations between the standards and indicators, this technique was identified and introduced as a suitable method for determining the importance coefficients of the criteria. In the next step, to determine an appropriate location for the establishment of sites for temporary accommodation, 9 effective variables in the form of 3 components (distance from disadvantages and incompatible uses, proximity to compatible uses, and natural criteria) were introduced and considered and the importance coefficients of each of these indicators were measured by applying a hierarchical analysis model. Then, by producing layers of information and through the overlapping of layers, suitable locations were identified and introduced.

The results of this study show that the points in the city with sufficient open spaces and still compatible with the surrounding uses, have a relatively better potential for settling the injured people. Although smooth lands around the study area provide the possibility of creating a camp, but distance from the service centers has made it undesirable. Therefore, it is better to avoid creating temporary accommodation in these areas.

According to the results of the study, land use indicators with a weight of 0.38 and distance from hazardous installations with a weight of 0.3 and their standards are more important in optimal site selection for temporary accommodation of the injured people.

Of compatible user criteria, accessibility criteria with a weight of 0.06 and proximity to the green space and park with a weight of 0.05 have a higher priority factors in locating. In addition, the results of this research are in line with some researches such as the study by (Katrina, 2011, and Giweh-chi et al., 2013) in the selection of various environmental and socioeconomic criteria for temporary accommodation site selection.

In Giweh-chi's research, the criterion of adequate access to temporary accommodation site selection is of great importance. In this research too, the access criteria in the dimension of compatible uses is among the key criteria.

In terms of incompatible use standards, distance from high voltage power lines with a weight of 0.085 and a population density of 0.080 is of a higher priority, which means that areas for temporary accommodation are suitable if they are away from these hazardous installations.

Finally, by integrating all the maps, the final map of the optimal site selection for the temporary accommodation base in Kamyaran was prepared and some areas were proposed as suitable locations for the establishment of settlement centers. The final site selection map showed that 381843.55 square meters had suitable and perfect conditions for the construction of temporary camps.

The results showed that the west and center of Kamyaran had the highest score for site selection for temporary settlement base, and the eastern part of the city was inadequate for temporary accommodation site selection.

\section{References}

[1] Abhari, M., Military Crisis Management, Malek Ashtar Industrial University Press, First Printing, 2007.

[2] Ziari, K., New City Planning, Second Edition, Samt Publishing, 2000.

[3] National Crisis Management Organization, Training Workshop and Crisis Management Staff Training, Ahvaz, 2009.

[4] Sahami, H., Planning and Locating, Malek Ashtar Industrial University Press, First Printing, 2007.

[5] Shokoei, H., Environmental Philosophy and Geography Schools, Geographical Institute Publication and Gitology Cartography, 2003.

[6] Shahabian, Sh., Theoretical Foundations of Spatial Locating, Shahrnegar Quarterly, No. 1997, 3.

[7] Shia, I., Introduction to the Basics of Urban Planning, University of Science and Technology, Tehran, 2005.

[8] Shoja'ian, A., Alizadeh, A. 2014. site selection Multi-Purpose Spaces with the Purpose of Crisis Management after the Earthquake, case study: Worn Textures in Shoshtar City, Geography Magazine and Urban-Regional Planning, Volume 4, Issue 11; Page 127 to page 140

[9] Samadzadegan, F., Abbaspour, A., Pahlavani, R., Parham. 2006. "Locating Emergency Accommodation Places for Citizens in Unexpected Accidents with the Use of Intelligent geographic information system (GIS), Conference on Information Technology and Natural Disaster Management

[10] Abdollahi, M., Crisis Management in Urban Areas, Publications of the Organization of Municipalities, Second Edition, Tehran, 20032009.

[11] Fallahi, A., Architecture of post-accident temporary settlements, Shahid Beheshti University Press, 2007.

[12] Mahmoudzadeh, A., and Pirasteh, S., Introduction to the Concepts of Crisis Management, Alam Afarin Publications, Isfahan, First Edition, 2009. 
[13] Mansoorian, A., Study of Geographic Information Systems in terms of Data Structure and Integration with Practical Testing, Khajeh Nasir Al-Din Toosi University, 1999

[14] Giweh-chi, S., et al. 2015. Site selection Temporary Resettlement after the Baccia Earthquake using GIS and AHP Technique, Case Study: Shiraz Sixth City, Journal of Urban and Regional Studies and Research, Vol. 5, No. 17.

[15] Vernosfaderny, Z. Zangi Abadi, A., Application of GIS in site selection temporary housing centers in Isfahan, GIS National Seminar on Economic, Social and Urban Planning

[16] Katerina, R., Donevska, V., \& Gorsevski. (2011). Regional non-hazardous land fill site selection by integrating fuzzy logic, AHP and geographic information systems, Environ Earth Sci, 67 (1), 121-131

[17] Close Tudes, Nazan Duygu Yigiter (2010), Preparation of land use planning model using GIS based on AHP, Case study AdanaTurkey, Bull Eng Geology Environment, 69: 235-245 